\title{
The Bioimpedance Spectroscopy as Useful Tool for Measuring the Fluid Excess and Fluid Management in Severe Polytrauma Patients
}

\author{
V. JOSKOVA ${ }^{1,2}$, A. PATKOVA ${ }^{1,2}$, E. HAVEL ${ }^{3}$, S. NAJPAVEROVA ${ }^{1}$, D. URAMOVA ${ }^{1}$, \\ M. KOVARIK ${ }^{1,2}$, Z. ZADAK ${ }^{2}$, M. HRONEK ${ }^{1,2}$
}

${ }^{1}$ Department of Biological and Medical Sciences, Faculty of Pharmacy in Hradec Kralove, Charles University, Hradec Kralove, Czech Republic, ${ }^{2}$ Department of Research and Development, University Hospital, Hradec Kralove, Czech Republic, ${ }^{3}$ Department of Surgery, University Hospital, Hradec Kralove, Czech Republic

Received June 3, 2018

Accepted October 31, 2018

Epub Ahead of Print January 10, 2019

\section{Summary}

Although the fluid therapy plays a fundamental role in the management of polytrauma patients (PP), a tool which could determine it appropriately is still lacking. The aim of this study was to evaluate the application of a bioimpedance spectroscopy (BIS) for body fluids volume and distribution monitoring in these patients. This prospective, observational study was performed on 25 severe PP and 25 healthy subjects. The body fluids composition was repeatedly assessed using BIS between days 3 to 11 of intensive care unit stay while the impact of fluid intake and balance was evaluated. Fluid intake correlated significantly with fluid excess (FE) in edemas, and their values were significantly higher in comparison with the control group. FE was strongly associated with cumulative fluid balance $(p<0.0001$, $r=0.719$ ). Furthermore, this parameter was associated with the entire duration of mechanical ventilation $(p=0.001, r=0.791)$ independently of injury severity score. In conclusion, BIS measured FE could be useful in PP who already achieved negative fluid balance in prevention the risk of repeated hypovolemia through inappropriate fluid restriction. What is more, measured FE has a certain prognostic value. Further studies are required to confirm BIS as a potential instrument for the improvement of PP outcome.

\section{Key words}

Bioimpedance spectroscopy • Fluid excess • Fluid balance • Fluid management $\bullet$ Mechanical ventilation • Critically ill patient

\section{Corresponding author}

M. Hronek, Faculty of Pharmacy, Educational and Research Center of Charles University, Zborovska 2089, Hradec Kralove, 500 03, Czech Republic. E-mail: hronek@faf.cuni.cz

\section{Introduction}

Critically ill patients are prone to develop changes in volume and distribution of body fluids (Malbrain et al. 2014a). The physiologic stress response to trauma induces fluid retention (Desborough 2000). This state is associated with damage to the cell membrane and loss of cellular integrity (Malbrain et al. 2014b). Increased vascular permeability develops a fluid shift from the intravascular to the interstitial space, promoting intravascular hypovolemia (Cotton et al. 2006). Treatment of this requires volume resuscitation (Upadya et al. 2005), in order to increase cardiac preload and cardiac output, thus potentially increasing blood pressure and microvascular blood flow, and maintaining organ perfusion (Wang et al. 2015). However, the administered fluids are not readily excreted, which may predispose the patient to postoperative fluid excess (FE) in peripheral tissues (Wang et al. 2015). Excessive fluid intake (FI) and prolonged administration may worsen the prognosis of patients. Several studies have demonstrated that a positive fluid balance (FB) is associated with a higher rate of complications and increased mortality in patients with acute renal failure (Wang et al. 2015) and acute lung injury (Sakr et al. 2005), as well as in the critically ill (Alsous et al. 2000, Elofson et al. 2015).

Unfortunately, little is known about how to monitor the amount and distribution of body fluids in polytrauma patients (PP), especially during the fluid mobilization phase (Malbrain et al. 2014a). De-escalation 
of i.v. FI together with diuretics treatment done with goal to promote a negative FB may cause repeated initiations of intravascular hypovolemia and worsening of oxygen supply to peripheral tissue. Assessment of fluid requirements usually includes dynamic indicators such as monitoring of blood pressure, heart rate, blood lactate levels, capillary refill, urine output and fluid balance are used (Hoste et al. 2014). However, accessible and applicable monitoring tools for determining the exact amount of retained fluids in the extracellular space is not available (Kayilioglu et al. 2015). Bioelectrical impedance spectroscopy (BIS) is a simple, non-invasive, rapid, portable method for measuring fluid distribution (Jaffrin and Morel 2008). This technique has been validated by isotope dilution methods (Buchholz et al. 2004, Moissl et al. 2006) and some previous studies suggest that BIS may provide useful information in critically ill patients undergoing fluid resuscitation (Malbrain et al. 2014a, Hannan et al. 1995, Finn et al. 1996, Plank et al. 1998). What is more, Hannan et al. derived an equation for the assessment of extracellular (ECW) and total body water (TBW) by multifrequency BIS in surgical patients, validating the technique against radioisotope dilution as an independent method (Hannan et al. 1998).

The aim of the present study was to analyze fluid changes in severe polytrauma patients during the time of their intensive care unit (ICU) stay and to determine if the BIS is a suitable tool for measuring fluid excess in PP, who achieved negative fluid balance, that could be useful in fluid management monitoring in this period, because that was not done and appropriate method is still lacking.

\section{Patients, Materials and Methods}

\section{Study design and populations}

This pilot prospective observational study was performed from January 2015 to June 2017 in the Surgical Intensive Care Unit at University hospital in Hradec Kralove. Twenty-five adult PP with the highest injury severity score (ISS) (Baker et al. 1974) were chosen according to the inclusion criteria (a minimum of two injuries, mechanically ventilated, and with volume resuscitation in response to shock). An equal number of healthy subjects (control group, CG) with similar anthropometric characteristics and age were also included. The exclusion criteria included age under 18 years, pregnancy, and contraindication for bioimpedance measurements (patients exhibiting massive cardiac decompensation or wearing a unipolar pacemaker). Bioimpedance spectroscopy and weighing were performed in the morning at the same time as about one hour after morning medication on selected days: for the first time on ICU day 3 or 4 (Period I), next in the period from day 5 to 7 (Period II), and the final examination during days 9 to 11 in ICU (Period III). The patients were followed up until death, ICU discharge, or for 11 days. BIS was measured in the CG for comparison.

No treatment and administration of intravenous fluid were affected. The treatment was standard according to the established practice of the ICU department. The study protocol strictly adhered to all provisions of the Declaration of Helsinki and was approved by the Ethics committee of the University Hospital in Hradec Kralove.

\section{Fluid management}

Due to the observational nature of this study, fluid management was left to the discretion of the attending physician. The main goal of volume therapy was to correct hypotension (mean arterial pressure $\geq 65 \mathrm{mmHg}$ ), restore diuresis to more than $0.5 \mathrm{ml} / \mathrm{kg} /$ hour, optimize peripheral tissue perfusion, and normalize high blood lactate levels $(\leq 2.0 \mathrm{mmol} / \mathrm{l})$. The effectiveness of the infusion therapy was monitored by dynamic indicators such as fluid challenge, pulse pressure variation, and a passive leg-raising test. Repeated physical examinations were carried out, such as capillary backflow in acral body parts, skin color changes, physical lung examination, filling of the neck veins, hepatojugular reflux etc.

\section{Anthropometry}

The patients were weighed with a specially calibrated bedscale to the nearest $0.1 \mathrm{~kg}$. Height was estimated from the measurement of the lower leg length from the top of the patella with the knee flexed at 90 degrees (Han and Lean 1996). The body weight of the control group was measured with an electronic balance (InnerScan Body Composition Monitor, Tanita Corporation, Tokyo, Japan), and height to the nearest $0.5 \mathrm{~cm}$ with a stadiometer. Weight and height were subsequently used to calculate body mass index as the ratio of weight in kilograms to the square of the height in meters.

\section{Fluid balance}

Daily FB was defined as the difference between 
total FI (fluids from all sources, including crystalloid and colloid infusions, nutrition, blood products, and medications) and the total output, which consisted of fluid loss through urinary, gastrointestinal, and other drainage tubes, and water losses from sweating and mechanical ventilation (MV). Evaporation was estimated based on the body temperature $\left(37^{\circ} \mathrm{C} \rightarrow 600 \mathrm{ml}\right.$; $38^{\circ} \mathrm{C} \rightarrow 800 \mathrm{ml} ; 39^{\circ} \mathrm{C} \rightarrow 1000 \mathrm{ml}$ ). Not only evaluation on a daily basis as this may fluctuate on the patient's condition during the different days, but also the cumulative fluid balance $(\mathrm{cFB})$ was calculated as the sum of all daily fluid balances up until the day of BIS measurement. All the values were recorded exactly from the rescue service intervention including emergency and surgery period, trough everyday of ICU stay.

\section{Bioimpedance spectroscopy}

BIS was performed with a Body Composition Monitor device - BCM (Fresenius Medical Care, Bad Homburg, Germany), which is able to be used in critically ill patients (Malbrain et al. 2014b); the instrument was regularly calibrated externally. Resistance $\left(\mathrm{R}_{\mathrm{F}}\right)$ and reactance were measured at 50 frequencies $(\mathrm{F})$ from $5 \mathrm{kHz}$ to $1 \mathrm{MHz}$. This device applies the Moissl equation (Moissl et al. 2006) for body composition, and the Chamney equation (Chamney et al. 2007) for FE for determination of edema. Other details of the methodological principles have been already described (Kyle et al. 2004). The measurements were taken using four adhesive surface electrodes: two attached at the wrist and two at the ankle on the same side of the body. Electrodes were placed on the undamaged side of the body after cleansing the skin with alcohol gauze. Patients and control subjects were in a supine position, with arms and legs abducted from the body in order to completely separate leg and arm tissue, with a rolled blanket placed snugly between the legs and between the arms and trunk. The following parameters calculated by the BCM Fresenius software were collected for each measurement: TBW, ECW, intracellular water (ICW), FE, and the ratio between extracellular and intracellular water (ECW/ICW). For comparison, the model for surgical patients was also applied, with calculation of extracellular water (ECW-S) and total body water (TBW-S) according to Hannan et al. (Hannan et al. 1998):

$$
\mathrm{ECW}-\mathrm{S}[\mathrm{l}]=\frac{0.178 \mathrm{H}^{2}}{R_{5}}+0.0688 \mathrm{~W}+3.77
$$

$$
\mathrm{TBW}-\mathrm{S}[\mathrm{l}]=\frac{0.239 H^{2}}{R_{200}}+0.189 \mathrm{~W}+2.97 \mathrm{~S}+5.46
$$

(W = weight $[\mathrm{kg}], \mathrm{H}=$ height $[\mathrm{cm}], \mathrm{S}=\operatorname{sex}$ (male $=1$, female $=0), R_{5 / 200}=$ resistance measured at frequency $5 / 200 \mathrm{kHz}[\Omega])$.

ICW-S was calculated as TBW-S - ECW-S. Healthy volunteers, constituting the control group, were measured in the fasted state in underwear. Triplicate measurements were carried out by standard procedures (see above) and averaged.

\section{Statistical analysis}

The acquired data were analyzed using the programs Graph-Pad Prism7 (GraphPad Software, La Jolla, CA, USA) and Excel 2016 (Microsoft, Redmont, WA, USA). All the parameters were evaluated by descriptive statistics and expressed as the mean $\pm \mathrm{SD}$ (standard deviation) or median (25\% percentile, $75 \%$ percentile) according to normality distribution demonstrated by D'Agostino and Pearson omnibus normality test. According to the normality of the distribution, ANOVA one-way test or Kruskal-Wallis test was applied to determine the difference between the observed parameters at various stages of hospitalization. An unpaired t-test or Mann Whitney test was used for comparison of PP and CG. A Mann Whitney test was used for comparison of ventilated and unventilated patients as well as the duration of mechanical ventilation, and a Wilcoxon matched-pairs signed rank test for the analysis of the two methods used to determine TBW, ECW, and ICW (BCM Fresenius software and the Hannan formula for surgical patients). Spearman's correlation $(\rho)$ was applied to evaluate the relationships between FI, FB and cFB with BIS data. All $p$ values were two-tailed and significance was accepted at $p<0.05$.

\section{Results}

The demographic profiles of PP and the control group are shown in Table 1. There were no significant differences between both groups. One male died whilst in intensive care. All patients experienced hemorrhagic shock. $70 \%$ of them received noradrenaline and all of them massive transfusion. It is of interest that patients with more packs of plasma or red blood cells needed shorter dosing regimen of noradrenaline $(p=0.021$, $r=-0.383$ ), which was indicated for a median 12.5 hours ( $25 \%$ percentile: 3 hours; $75 \% 32$ hours). Resuscitation 
shock phase lasted an average of 1.5 days. During this time, a total of $17720 \mathrm{ml}$ fluids on average were administered, of which $30 \%$ consisted of blood derivatives. On average, $1971 \mathrm{ml}$ of packed red blood cells, $2184 \mathrm{ml}$ plasma and $755 \mathrm{ml}$ of thrombocyte were indicated.

From the third day of ICU hospitalization, the patients achieved a negative FB (on average $-382 \mathrm{ml}$ ). The daily fluid intake correlated with daily fluid balance during the whole observation period $(p<0.001 ; r=0.879)$, however it was not associated with diuresis per 24 hours $(p=0.744 ; r=-0.022)$.

The amount and distribution of body fluids including fluid excess (FE) are presented in Table 2 for $\mathrm{PP}$ as well as CG. There were no significant differences between the measurements obtained using the BCM Fresenius software and those calculated according to the Hannan formula. The correlation analysis of the data obtained by these two ways is illustrated in Fig. 1 A, B.

Table 1. Baseline characteristics of polytrauma patients and healthy control group

\begin{tabular}{|c|c|c|c|}
\hline & $\begin{array}{l}\text { Polytrauma patients } \\
\qquad(n=25)\end{array}$ & $\begin{array}{l}\text { Control group } \\
\qquad(n=25)\end{array}$ & $P$-value \\
\hline Female $[\%]$ & 20 & 20 & - \\
\hline Age [years] & $50.43 \pm 18.71$ & $49.62 \pm 18.7$ & 0.89 \\
\hline Height $[\mathrm{cm}]$ & $174.10 \pm 7.90$ & $176.60 \pm 8.68$ & 0.34 \\
\hline Body weight [kg] & $97.44 \pm 18.01$ & $92.36 \pm 19.71$ & 0.39 \\
\hline Body mass index $\left[\mathrm{kg} / \mathrm{m}^{2}\right]$ & $31.96 \pm 4.95$ & $29.54 \pm 5.58$ & 0.14 \\
\hline Injury severity score & $33.47 \pm 11.42$ & - & - \\
\hline Mechanical ventilation [hours] & $285.20 \pm 297.90$ & - & - \\
\hline Intensive care unit stay [days] & $25.27 \pm 21.54$ & - & - \\
\hline Length of hospital stay [days] & $57.11 \pm 65.45$ & - & - \\
\hline
\end{tabular}

Values are expressed as mean $\pm \mathrm{SD}$.

Table 2. Bioimpedance spectroscopy measurement in polytrauma patients in three periods during intensive care unit stay and in healthy control group

\begin{tabular}{lcccc}
\hline & 3-4 day of ICU stay & $\mathbf{5 - 7}$ day of ICU stay & $\mathbf{9 - 1 1}$ day of ICU stay & Control group \\
\hline$n M N P$ & 18 & 16 & 12 & - \\
$T B W[l]$ & $50.5(42.5 ; 59.8)^{*}$ & $50.10(40.75 ; 56.35)$ & $47.8(39.98 ; 58.4)$ & $44.6(36.65 ; 49.7)$ \\
$T B W-S[l]$ & $53.45(42.83 ; 59.76)^{*}$ & $50.07(39.34 ; 54.54)$ & $50.76(38.52 ; 56.87)$ & - \\
$E C W[l]$ & $28.2(20.55 ; 32.8)^{* * *}$ & $26.45(20.50 ; 30.13)^{* *}$ & $27.45(17.8 ; 29.9)^{*}$ & $19.8(16.65 ; 22.4)$ \\
$E C W-S[l]$ & $27.34(20.83 ; 31.2)^{* * * *}$ & $25.82(21.11 ; 29.42)^{* *}$ & $26.64(18.5 ; 28.57)^{* *}$ & - \\
$I C W[l]$ & $24.9(19.05 ; 29)$ & $23.85(17.25 ; 27.00)$ & $22.35(18.9 ; 26.98)$ & $24.7(19.9 ; 26.65)$ \\
$I C W-S[l]$ & $24.36(21.71 ; 28.25)$ & $24.16(17.35 ; 26.49)$ & $24.47(18.93 ; 28.71)$ & - \\
$E C W / I C W$ & $1.12(0.995 ; 1.29)^{* * * *}$ & $1.20(0.83 ; 1.45)^{* *}$ & $1.1(0.80 ; 1.35)^{*}$ & $0.83(0.77 ; 0.91)$ \\
$E C W-S / I C W-S$ & $1.09(0.977 ; 1.17)^{* * * *}$ & $1.20(0.97 ; 1.27)^{* * * *}$ & $1.031(0.97 ; 1.13)^{* * * *}$ & - \\
$F E[l]$ & $6.6(3.8 ; 10.85)^{* * * *}$ & $9.3(2.5 ; 17.2)^{* * * *}$ & $6.45(2.3 ; 9.9)^{* * * *}$ & $0(-0.95 ; 0.6)$ \\
$E C W-F E[l]$ & $18.9(16.6 ; 22.45)$ & $17.45(15.55 ; 21.2)$ & $18.3(14.98 ; 23.45)$ & - \\
\hline
\end{tabular}

Values are expressed as median (25\% percentile; $75 \%$ percentile). ${ }^{*} \mathrm{P}<0.05 ;{ }^{*} * \mathrm{P}<0.01 ;{ }^{*} * * \mathrm{P}<0.001 ; * * * * \mathrm{P}<0.0001$ versus control group. ICU: intensive care unit; $n$ MVP: number of mechanically ventilated patients; BIS: parameters according to Body Composition Monitor (TBW: total body water; ECW: extracellular water; ICW: intracellular water; FE: fluid excess), and according to the Hannan model for surgical patients (TBW-S, ECW-S, ICW-S). 


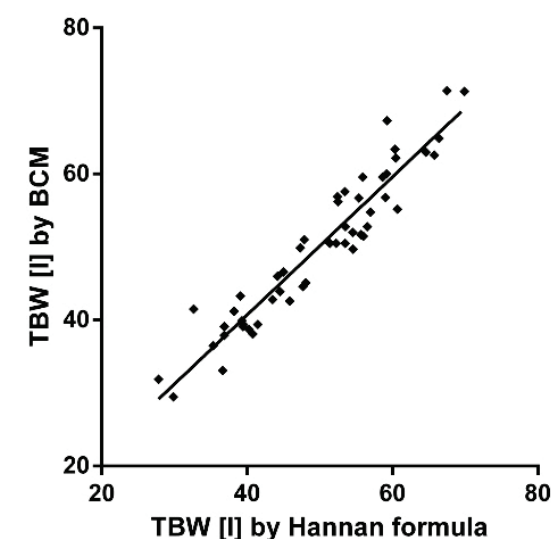

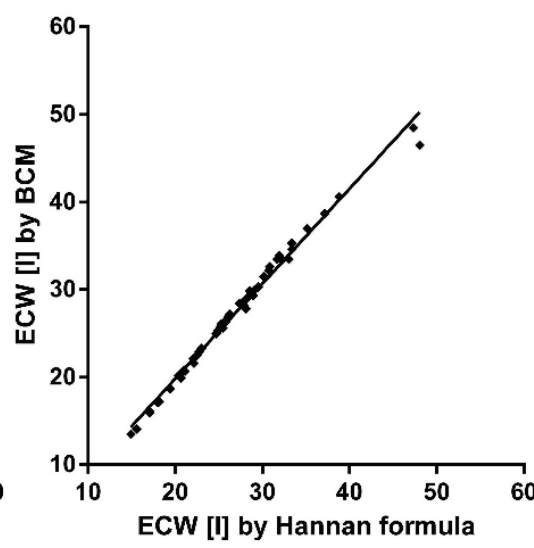

B

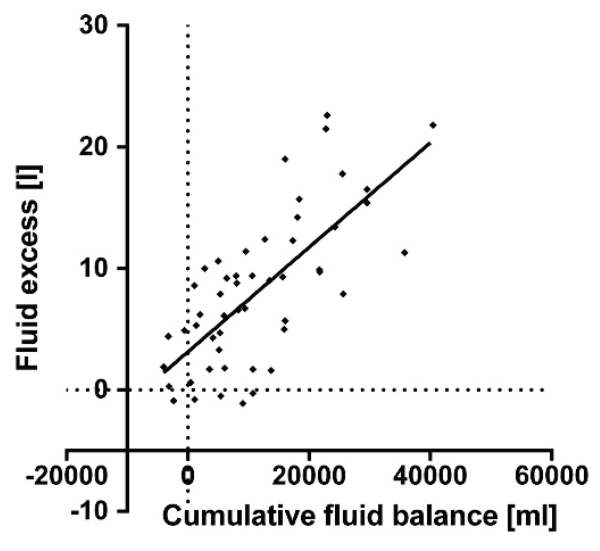

C

Fig. 1. A) Linear regression between TBW measured by BCM and TBW calculated by model for surgical patients according to Hannan formula ( $(<0.0001, r=0.905)$; B) Linear regression between ECW measured by BCM and ECW calculated by model for surgical patients according to Hannan formula $(\mathrm{p}<0.0001, \mathrm{r}=0.990)$; C) Linear regression between cumulative fluid balance and fluid excess from day 3 to day 11 of intensive care unit stay $(p<0.0001, r=0.719)$, TBW: total body water; ECW: extracellular water; BCM: Body Composition Monitor (Fresenius).

Table 3. Correlation analysis between FI, FB, cFB and BIS parameters from the third day of ICU stay to day 11

\begin{tabular}{|c|c|c|c|c|c|c|c|c|c|}
\hline & \multicolumn{3}{|c|}{ 3-4 d of ICU stay } & \multicolumn{3}{|c|}{ 5-7 d of ICU stay } & \multicolumn{3}{|c|}{ 9-11 d of ICU stay } \\
\hline & FI (I) & FB (I) & cFB (I) & FI (II) & FB (II) & cFB (II) & FI (III) & FB (III) & cFB (III) \\
\hline$F E$ & $0.593 * *$ & $0.648 * * *$ & $0.677 * * *$ & $0.658 * *$ & $0.684 * * *$ & $0.712 * * *$ & $0.657 *$ & 0.343 & $0.627 *$ \\
\hline$T B W$ & 0.361 & 0.105 & $0.584 * *$ & 0.385 & 0.181 & $0.695^{* * *}$ & 0.133 & -0.175 & 0.009 \\
\hline$E C W$ & $0.563^{* *}$ & $0.485^{*}$ & $0.761 * * * *$ & $0.618^{* *}$ & $0.537^{*}$ & $0.811 * * * *$ & 0.508 & 0.137 & 0.318 \\
\hline$I C W$ & 0.118 & -0.191 & 0.293 & 0.070 & 0.121 & 0.229 & -0.098 & -0.196 & -0.273 \\
\hline$E C W / I C W$ & 0.323 & $0.579 * *$ & 0.362 & $0.614 * *$ & $0.558^{*}$ & $0.512^{*}$ & $0.594^{*}$ & 0.287 & 0.491 \\
\hline$F B$ & $0.619 * *$ & - & 0.366 & $0.645 * *$ & - & 0.386 & $0.734 * *$ & - & 0.582 \\
\hline$c F B$ & 0.349 & 0.366 & - & $0.516^{*}$ & 0.386 & - & $0.827 * *$ & 0.582 & - \\
\hline
\end{tabular}

Values are expressed as Spearman correlation coefficient. $* P<0.05 ; * * P<0.01 ; * * * P<0.001 ; * * * *<0.0001$ according to $P$ value of correlation analysis. d: day; FI: fluid intake; FB: fluid balance; cFB: cumulative fluid balance; FE: fluid excess; TBW: total body water; ECW: extracellular water; ICW: intracellular water; ICU: intensive care unit; BIS: bioimpedance spectroscopy.

Further, no significant differences were observed in fluid volume through the different phases of ICU stay using BIS method. However, TBW, ECW, ECW/ICW, and FE were significantly lower in $\mathrm{CG}$ in comparison with PP; the amount of intracellular fluid was the only parameter which did not differ between the groups. After deduction of FE from amount of ECW in PP, these values were not significantly different from ECW in CG.

Table 3 shows the results of the correlation analysis between parameters measured by BIS in each period of ICU hospitalization and FI, FB, and $\mathrm{cFB}$ for those days. From the obtained data we can consider that fluid intake contributed to a significant increment of FE and ECW; however, it did not show a significant increment in TBW or ICW. There were strong correlations between $\mathrm{FE}$ and $\mathrm{FB}$; furthermore, $\mathrm{cFB}$ was associated with higher FE significantly (Fig. 1C). TBW and ECW correlated with cumulative fluid balance in the first week of ICU stay.

All the patients had to be mechanically ventilated at the beginning of ICU stay. During the study period from day 3 to 4 of ICU stay, some of the patients were ventilated mechanically, while others breathed spontaneously. Patients who had been weaned from mechanical ventilation during these days showed a lower FE $(\tilde{x}=4.31)$ compared to ventilated patients $(\tilde{x}=10.91)$ $(p=0.004)$ (Fig. 2A), despite these two groups of patients not showing any difference in ISS $(p=0.176)$. Furthermore, fluid excess measured during hospital days 5-7 was associated significantly with the entire duration 
of mechanical ventilation according to equation $\mathrm{MV}[\mathrm{h}]=24.722 \mathrm{FE}[1]+125.24(p=0.001, r=0.791)$. The median duration of mechanical ventilation was $306 \mathrm{~h}$ (about 12 days). It is of interest that those patients who had been ventilated for more than 306 hours showed a significant increment in fluid excess $\tilde{x}=15.41$ during study period II in comparison with only 1.71 for PP who had been weaned earlier from the ventilator $(p=0.002)$ (Fig. 2 B). Again, these groups did not differ in ISS.
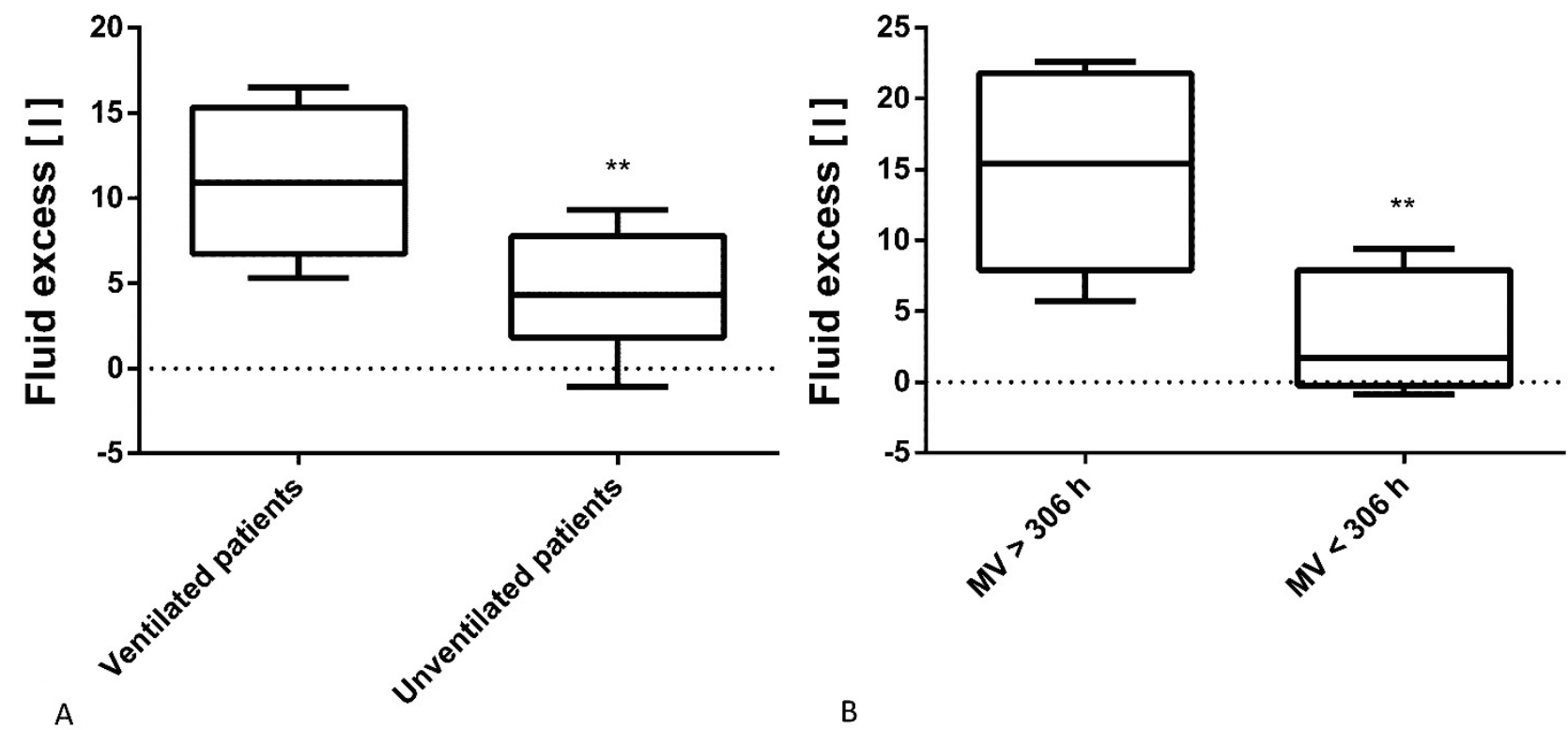

Fig. 2. A) The FE measured on hospital days $3-4$ in ventilated and unventilated patients; B) The FE measured on hospital days $5-7$ in patients mechanically ventilated for more than 306 hours and less than $306 \mathrm{~h}$. Values are expressed as median (min to max). ${ }^{* *} p<0.01$, MV: mechanical ventilation; FE: fluid excess.

\section{Discussion}

To the best of our knowledge, this is the first study addressing the BIS method and its parameters in relation to the amount of fluid intake and balance in severe PP. All PP meeting the criteria were included in the study, consisting of serious surgical patients with very high ISS and fluid retention level. In contrast, mortality was only $4 \%$ and there was no development of renal insufficiency requiring dialysis. From the third day of ICU stay, PP achieved a negative FB on average similarly to that reported in previous studies (Alsous et al. 2000, Upadya et al. 2005). From this time there is a risk of overhydration with harmful consequences (Elofson et al. 2015), but also of recurring dehydration by gradually reducing fluid intake during the fluid mobilization phase, which is also undesirable effect with risk of intravascular hypovolemia and low oxygen supplementation to peripheral tissues (Hoste et al. 2014).

Unfortunately, the optimal methodology to assess volume status after initial fluid resuscitation remains to be determined. There are several approaches to detect the body hydration of the patient, which differ in many aspects. The central venous pressure is one of the most frequently used variables to guide fluid resuscitation in critically ill patients (De Backer and Vincent 2018). However, recent studies describe controversial benefits and many limitations that influence the measurement, among others mechanical ventilation, which is almost always indicated in PP (Marik and Cavallazzi 2013). Another available methods are ultrasound measurement of inferior vena cava that can be used for assessment of intravascular volume status or thoracic ultrasound with B-line detection which can evaluate fluid overload in the lungs (Claure-Del Granado and Mehta 2016). In addition to these methods, it would be also beneficial to determine the water content of each compartment in PP. Therefore, the aim of this pilot study was to verify our hypothesis, that simple noninvasive method BIS, which is able to measure amount and distribution of body water, could be useful in PP after achieving negative fluid balance.

This study is unique in that not only standard FB was calculated, but also that BIS was applied to measure body fluid parameters such as TBW, ECW, ICW and FE. 
Fluid balance was recorded from the first patients contact with the health care service; the monitoring of patients by BIS was performed from the third ICU day for first two days very individual changes in fluid status and fluid therapy according to the acute condition of the patient.

We are aware that some distortion of the results in patients with multiple fractures could be present, and for this reason, we measured BIS exclusively at undamaged sites. The variability of repeated measurements corresponded to the standard deviation of the device manufacturer. The coefficient of variation of intrapersonal measurement was up to $0.5 \%$. Furthermore, we deducted the value of FE from the amount of ECW and discovered that this does not significantly differ from the ECW of healthy CG. Thus, this is an indirect validation of the BCM device measurement and the accuracy of the acquired data. In addition, these data are not different from values calculated according to the special Hannan formula for surgical patients, which was also used in this study (Hannan et al. 1998). It was concluded, as in a previous study (Malbrain et al. 2014b), that a $\mathrm{BCM}$ can be used to measure body fluid volumes in critically ill patients with fluid distortion. On the other hand, the findings of this study will be also useful, at workplaces with other BIS instruments for the determination of body fluids by both using resistance measurement at certain frequencies and the application of equation by Hannan et al. (1998). This could be useful especially during the fluid mobilization phase, when there is a big risk of dehydration. Our results show that the developed changes in the amount and distribution of body fluids are of an individual nature because of the several factors influencing the hydration status. On the other hand, strong differences have been confirmed between PP and CG, as shown in another study (Malbrain et al. 2014a). While TBW, ECW, and FE were significantly lower in CG than in PP, the amount of intracellular fluid did not differ.

Throughout the whole study period, fluid intake contributed to an increased FB in PP. Using BIS, the obtained results suggest that FI according to the analyzed parameters contributes significantly to increased ECW and FE, not ICW. Furthermore, PP were different precisely in these parameters when compared to healthy individuals. Therefore, one of the factors leading to increased amount of fluid in the extracellular space is probably volume intake, which consists of fluid from infusions, blood products, medications, and nutrition as well as creation of metabolic water from oxidation of nutritional substrates. It is known that each liter of FB is associated with a $10 \%$ increment in mortality (Vincent $e t$ al. 2006). According to our study, changes in $\mathrm{cFB}$ are reflected by the value of FE. Just this value could help to indicate if the patient is still retaining a certain amount of fluid in extracellular space, even if the fluid balance is already equal to zero. Similarly, Dewitte et al. described the association between the BIS parameter (TBW) and FB during the first 3 days after ICU admission in critically ill patients (Dewitte et al. 2016), associating fluid overload with peripheral edema. This is most evident in the lungs, potentially leading to acute pulmonary edema or acute respiratory distress syndrome (Claure-Del Granado and Mehta 2016), and it can delay weaning from mechanical ventilation. In our study, FE as determined by $\mathrm{BCM}$, correlated to the duration of mechanical ventilation independently of the ISS. Patients were weaned from ventilator according an international consensus conference on weaning (resolution of disease for which the patient was intubated, cardiovascular stability with no need or minimal vasopressors, no continuous sedation and adequate oxygenation defined as $\mathrm{paO}_{2} / \mathrm{FiO}_{2}$ of at least $150 \mathrm{mmHg}$ with positive endexpiratory pressure (PEEP) up to $8 \mathrm{cmH}_{2} \mathrm{O}$ ) (Thille et al. 2013). Using BIS, it can be estimated, with a high degree of probability, for how long the patient will have to be mechanically ventilated if we measure FE on ICU days 5-7. In addition, other studies have demonstrated that higher values for some BIS parameters indicate worse outcomes. Dabrowski et al. (2014) found a sustained elevation in TBW, ECW, ECW/ICW ratio, and FE in non-survivors compared with survivors among septic shock patients (Dabrowski et al. 2014, Malbrain et al. 2014a). Recent study described that BIS can be used to predict hospital mortality, duration of ventilator use and ICU stay in critically ill patients by the increased FE values (Yang et al. 2017).

This study has several important limitations, most notably is the number of patients included. This is the pilot study in which the small cohort was due to the limited number of patients with such severe injuries and high ISS score at the University Hospital in Hradec Kralove, Czech Republic during 3 years. It is also the reason, why only few studies have been conducted on a polytrauma population. Even so, our results were found to be significant. Regardless, further study is definitely needed to confirm the obtained data. Another limitation was that the radioisotope methods to estimate body water volume were not used, because multifrequency BIS has 
been validated (Hannan et al. 1995, Hannan et al. 1998) and has been shown as highly reproducible in critically ill patients, with a mean coefficient of variation of $0.9 \%$ for ECW and $0.6 \%$ for TBW, corresponding to 0.151 and 0.191 (Hannan et al. 1995).

In conclusion this is the first study which measured the extra fluid volume in extracellular space as a value called fluid excess in group of severe polytrauma patients by exact method - bioimpedance spectroscopy, instead of estimating the fluid balance only. The fluid was accumulated exclusively in the extracellular space. On average, this FE value was reached up to 9.31 . Especially when patients achieve a negative fluid balance, it is very difficult to estimate fluid management with risk of hypovolemia and dehydration with a negative impact on the oxygen supply to peripheral tissues. BIS could thus help to indicate the appropriate amount of fluid intake and doses of diuretics according to the amount of fluid excess. What is more, it has been shown that this parameter has a certain prognostic value for the length of mechanical ventilation. Further studies are required to confirm BIS as a potential instrument for the improvement of PP outcome.

\section{Conflict of Interest}

Authors declare that they have no conflict of interest.

\section{Acknowledgements}

The authors are thankful to the staff of the Surgical ICU 1 of the University Hospital in Hradec Kralove. The authors would also like to express their gratitude to Ian McColl, MD. Ph.D. for assistance in proofreading the manuscript. This work was supported by the Charles University Grant Agency [project GA UK 772216], the Specific Scientific Academic Research Projects of Charles University [SVV/2018/260417], the Development and Research of Drugs of Charles University [PROGRES Q42] and Ministry of Health Czech Republic - Development of Research Organization (University Hospital Hradec Kralove) [MH CZ - DRO UHHK 00179906].

\begin{abstract}
Abbreviations
BCM, Body Composition Monitor; BIS, bioelectrical impedance spectroscopy; cFB, cumulative fluid balance; CG, control group; ECW, extracellular water (according to Body Composition Monitor); ECW-S, extracellular water (according to Hannan model for surgical patients); $\mathrm{ECW} / \mathrm{ICW}$, ratio between extracellular and intracellular water; F, frequency; FB, fluid balance; FE, fluid excess; FI, fluid intake; ICU, intensive care unit; ICW, intracellular water (according to Body Composition Monitor); ICW-S, intracellular water (according to Hannan model for surgical patients); ISS, injury severity score; MV, mechanical ventilation; PP, polytrauma patients; $\mathrm{R}_{\mathrm{F}}$, resistance measured at a certain frequency; SD, standard deviation; TBW, total body water (according to Body Composition Monitor); TBW-S; total body water (according to Hannan model for surgical patients)
\end{abstract}

\section{References}

ALSOUS F, KHAMIEES M, DEGIROLAMO A, AMOATENG-ADJEPONG Y, MANTHOUS CA: Negative fluid balance predicts survival in patients with septic shock: a retrospective pilot study. Chest 117: 1749-1754, 2000.

BAKER SP, O'NEILL B, HADDON W, JR, LONG WB: The injury severity score: a method for describing patients with multiple injuries and evaluating emergency care. J Trauma 14: 187-196, 1974.

BUCHHOLZ AC, BARTOK C, SCHOELLER DA: The validity of bioelectrical impedance models in clinical populations. Nutr Clin Pract 19: 433-446, 2004.

CHAMNEY PW, WABEL P, MOISSL UM, MULLER MJ, BOSY-WESTPHAL A, KORTH O, FULLER NJ: A whole-body model to distinguish excess fluid from the hydration of major body tissues. Am J Clin Nutr $\mathbf{8 5}$ : 80-89, 2007.

CLAURE-DEL GRANADO R, MEHTA RL: Fluid overload in the ICU: evaluation and management. BMC Nephrol 17: 109, 2016.

COTTON BA, GUY JS, MORRIS JA, JR, ABUMRAD NN: The cellular, metabolic, and systemic consequences of aggressive fluid resuscitation strategies. Shock 26: 115-121, 2006.

DABROWSKI W, KOTLINSKA-HASIEC E, SCHNEDITZ D, ZALUSKA W, RZECKI Z, DE KEULENAER B, MALBRAIN ML: Continuous veno-venous hemofiltration to adjust fluid volume excess in septic shock patients reduces intra-abdominal pressure. Clin Nephrol 82: 41-50, 2014. 
DE BACKER D, VINCENT JL: Should we measure the central venous pressure to guide fluid management? Ten answers to 10 questions. Crit Care 22: 43, 2018.

DESBOROUGH JP: The stress response to trauma and surgery. Br J Anaesth 85: 109-117, 2000.

DEWITTE A, CARLES P, JOANNES-BOYAU O, FLEUREAU C, ROZE H, COMBE C, OUATTARA A: Bioelectrical impedance spectroscopy to estimate fluid balance in critically ill patients. J Clin Monit Comput 30: 227-233, 2016.

ELOFSON KA, EIFERMAN DS, PORTER K, MURPHY CV: Impact of late fluid balance on clinical outcomes in the critically ill surgical and trauma population. J Crit Care 30: 1338-1343, 2015.

FINN PJ, PLANK LD, CLARK MA, CONNOLLY AB, HILL GL: Progressive cellular dehydration and proteolysis in critically ill patients. Lancet 347: 654-656, 1996.

HAN TS, LEAN ME: Lower leg length as an index of stature in adults. Int J Obes Relat Metab Disord 20: 21-27, 1996.

HANNAN WJ, COWEN SJ, PLESTER C, FEARON KC: Proximal and distal measurements of extracellular and total body water by multi-frequency bio-impedance analysis in surgical patients. Appl Radiat Isot 49: 621-622, 1998.

HANNAN WJ, COWEN SJ, PLESTER CE, FEARON KC, DEBEAU A: Comparison of bio-impedance spectroscopy and multi-frequency bio-impedance analysis for the assessment of extracellular and total body water in surgical patients. Clin Sci (Lond) 89: 651-658, 1995.

HOSTE EA, MAITLAND K, BRUDNEY CS, MEHTA R, VINCENT JL, YATES D, KELLUM JA, MYTHEN MG, SHAW AD, GROUP AXI: Four phases of intravenous fluid therapy: a conceptual model. Br J Anaesth 113: 740-747, 2014.

JAFFRIN MY, MOREL H: Body fluid volumes measurements by impedance: A review of bioimpedance spectroscopy (BIS) and bioimpedance analysis (BIA) methods. Med Eng Phys 30: 1257-1269, 2008.

KAYILIOGLU SI, DINC T, SOZEN I, BOSTANOGLU A, CETE M, COSKUN F: Postoperative fluid management. World J Crit Care Med 4: 192-201, 2015.

KYLE UG, BOSAEUS I, DE LORENZO AD, DEURENBERG P, ELIA M, GOMEZ JM, HEITMANN BL, KENTSMITH L, MELCHIOR JC, PIRLICH M, SCHARFETTER H, SCHOLS AM, PICHARD C, COMPOSITION OF THE EWG: Bioelectrical impedance analysis--part I: review of principles and methods. Clin Nutr 23: 1226-1243, 2004.

MALBRAIN ML, HUYGH J, DABROWSKI W, DE WAELE JJ, STAELENS A, WAUTERS J: The use of bio-electrical impedance analysis (BIA) to guide fluid management, resuscitation and deresuscitation in critically ill patients: a bench-to-bedside review. Anaesthesiol Intensive Ther 46: 381-391, 2014a.

MALBRAIN ML, HUYGH J, WAUTERS J: The Role for Bio-Electrical Impedance Analysis in Critically Ill Patients. ICU Management \& Practice 14: 2014b.

MARIK PE, CAVALLAZZI R: Does the central venous pressure predict fluid responsiveness? An updated metaanalysis and a plea for some common sense. Crit Care Med 41: 1774-1781, 2013.

MOISSL UM, WABEL P, CHAMNEY PW, BOSAEUS I, LEVIN NW, BOSY-WESTPHAL A, KORTH O, MULLER MJ, ELLEGARD L, MALMROS V, KAITWATCHARACHAI C, KUHLMANN MK, ZHU F, FULLER NJ: Body fluid volume determination via body composition spectroscopy in health and disease. Physiol Meas 27: 921-933, 2006.

PLANK LD, MONK DN, WOOLLARD GA, HILL GL: Evaluation of multifrequency bioimpedance spectroscopy for measurement of the extracellular water space in critically ill patients. Appl Radiat Isot 49: 481-483, 1998.

SAKR Y, VINCENT JL, REINHART K, GROENEVELD J, MICHALOPOULOS A, SPRUNG CL, ARTIGAS A, RANIERI VM, SEPSIS OCCURENCE IN ACUTELY ILL PATIENTS I: High tidal volume and positive fluid balance are associated with worse outcome in acute lung injury. Chest 128: 3098-3108, 2005.

THILLE AW, CORTES-PUCH I, ESTEBAN A: Weaning from the ventilator and extubation in ICU. Curr Opin Crit Care 19: 57-64, 2013.

UPADYA A, TILLUCKDHARRY L, MURALIDHARAN V, AMOATENG-ADJEPONG Y, MANTHOUS CA: Fluid balance and weaning outcomes. Intensive Care Med 31: 1643-1647, 2005. 
VINCENT JL, SAKR Y, SPRUNG CL, RANIERI VM, REINHART K, GERLACH H, MORENO R, CARLET J, LE GALL JR, PAYEN D, SEPSIS OCCURRENCE IN ACUTELY ILL PATIENTS I: Sepsis in European intensive care units: results of the SOAP study. Crit Care Med 34: 344-353, 2006.

WANG N, JIANG L, ZHU B, WEN Y, XI XM, BEIJING ACUTE KIDNEY INJURY TRIAL W: Fluid balance and mortality in critically ill patients with acute kidney injury: a multicenter prospective epidemiological study. Crit Care 19: 371, 2015.

YANG SF, TSENG CM, LIU IF, TSAI SH, KUO WS, TSAO TP: Clinical Significance of Bioimpedance Spectroscopy in Critically Ill Patients. J Intensive Care Med 885066617702591, 2017. 